\title{
Gouty Tophus: Cytological Findings in a Case Diagnosed by Fine Needle Aspiration
}

\author{
J. Ortiz*, L. M. Chinchilla, E. Muñoz, M. D. Ludeña \\ Department of Pathology, University Hospital of Salamanca, Salamanca, Spain \\ Email: ‘jortiz@usal.es
}

How to cite this paper: Ortiz, J., Chinchilla, L.M., Muñoz, E. and Ludeña, M.D. (2018) Gouty Tophus: Cytological Findings in a Case Diagnosed by Fine Needle Aspiration. Open Journal of Pathology, 8, 47-50. https://doi.org/10.4236/ojpathology.2018.8 $\underline{1005}$

Received: November 15, 2017

Accepted: January 12, 2018

Published: January 15, 2018

Copyright $\odot 2018$ by authors and Scientific Research Publishing Inc. This work is licensed under the Creative Commons Attribution International License (CC BY 4.0).

http://creativecommons.org/licenses/by/4.0/

\begin{abstract}
A case of gouty tophus in the elbow of a 62-year-old male is presented. Fineneedle aspiration (FNA) revealed the presence of acicular crystals, birefringent when viewed under polarized light as is typical for monosodium urate crystals. Histological study of the removed lesion confirmed a typical gouty tophus. We briefly comment the main characteristics of this entity.
\end{abstract}

\section{Keywords}

Fine-Needle Aspiration (FNA), Gouty Tophus, Cytopathology

\section{Introduction}

The indisputable advantages (simplicity, rapidity, reproducibility, innocuousness and low cost) of FNA for the study of accessible lesions, either by palpation, radiology or endoscopy, have led to the rapid expansion of this technique for the study of a wide range of pathologies.

Although clinically common, tophus lesions are rarely brought to pathological study, and their cytological descriptions are scarce in the medical literature.

\section{Clinical Case}

A 62-year-oldman presented with a white-yellow wish periarticular mass in the elbow that grew slowly over several months up to $5 \mathrm{~cm}$ in diameter. Its consistency was soft, and there were no inflammatory data. An oily material was obtained by FNA. The microscopic study of $96^{\circ}$ ethanol fixed smears stained with hematoxylin-eosin and Papanicolau, showed collections of an acicular and crystalloid material. Sometimes, they were accompanied by multinucleated giant cells. This material was birefringent on polarized light (Figure 1(a) and Figure $1(b))$. 


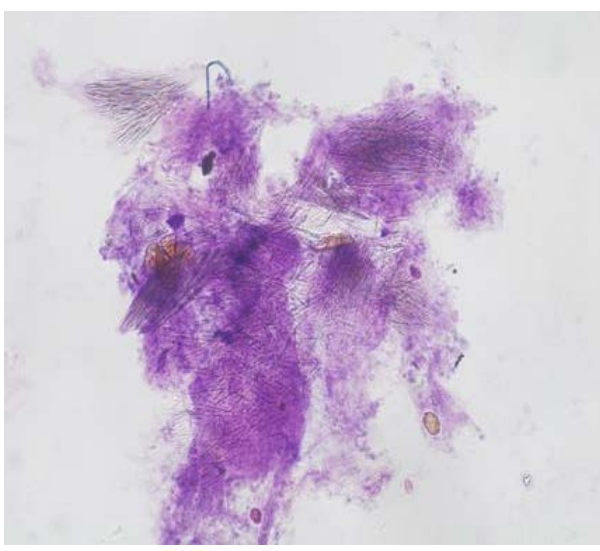

(a)

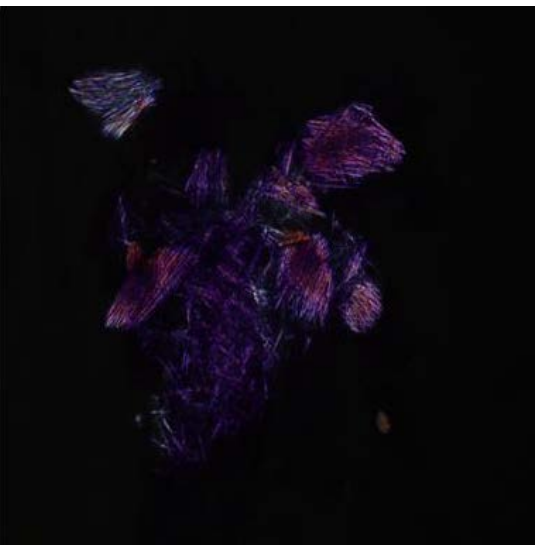

(b)

Figure 1. (a) Gouty tophus (FNA): accumulations of acicular crystalline material (He $\times 200$ ); (b) Gouty tophus (FNA): birefringence under polarized light.

With the suspicion of gouty tophus, the injury was removed. Histological study confirmed the diagnosis. Revealing a typical picture with accumulations of monosodium urate crystals surrounded by giant histiocytic cells (Figure 2(a) and Figure 2(b)).

\section{Discussion}

The presence of uric acid crystals surrounded by macrophagic-histiocytic cells constitutes the basic histological finding of tophaceous gout [1] [2]. Tophi are pathognomonic forgout, a hyperuricemia related with disease characterised by recurrent acute mono- or oligoarthritis. Partly genetic, hyperuricemia is frequently associated with other common medical conditions, such as metabolic syndrome, obesity, insulin resistance myeloproliferative disorders and other less prevalent medical problems. An iatrogenic character related to such widely used drugs as aspirin, diuretics, ACE inhibitors or beta and angiotensin receptor blockers, is also usual [3] [4]. Tophi are to be found in articular and periarticular tissues, bone, and other areas. Their histological appearance is pathognomonic. However, tophi have been infrequently described in the field of Cytology, and most specifically, as already mentioned, case-reports using FNA. The cytological characteristics of our cases have the same pattern described in the literature [5] [6] [7].

Considering the later, we contemplated a differential diagnosis with entities which have similar characteristics, such as epidermic cysts (keratin material), foreign-body inflammatory reactions, or hyperoxalosis (calcium oxalate crystals) [8] [9] [10]. Our first diagnosis was confirmed after the histological procedures and the high-level hyperuricemia $(12 \mathrm{mg} / 100 \mathrm{~mL})$ in his laboratory tests. Two years after the surgical procedure and maintaining a specific diet combined with an Allopurinol treatment, the symptomatology has totally disappeared.

Finally, we would like to highlight the great importance of the histological and cytological knowledge for specific purposes, and the importance of adequate 


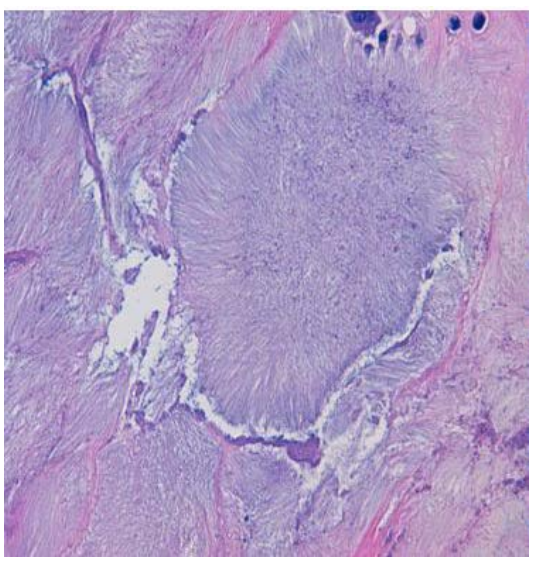

(a)

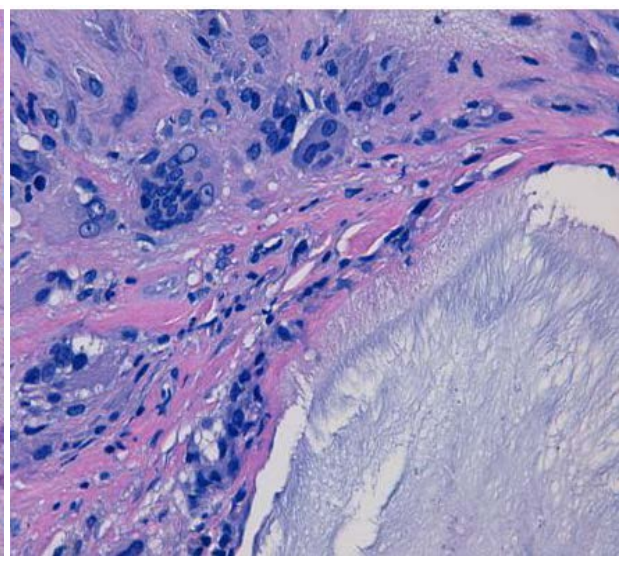

(b)

Figure 2. (a) Gouty tophus (biopsy): acicular accumulations of uric acid ( $\mathrm{He} \times 200)$; (b) Gouty tophus (biopsy): acicular accumulations of uric acid, surrounded by multinucleated giant cells $(\mathrm{He} \times 400)$.

communication between clinicians and pathologists.

\section{References}

[1] Willner, N., Monoranu, C.M., Stetter, C., Ernestus, R.I. and Westermaier, T. (2016) Gout Tophus on an Intradural Fascicle: A Case Description. European Spine Journal, 25, 162-166. https://doi.org/10.1007/s00586-015-4309-Z

[2] Zhou, C., Xue, C., Yang, B., Wang, W., Xu, Y., Huang, F. and Wang, Y. (2017) Amputation of the First Metatarsophalangeal Joint Due to a Giant Gouty Tophi: A Case Report. Medicine (Baltimore), 96, Article ID: e8441.

https://doi.org/10.1097/MD.0000000000008441

[3] Cairo, M.S., Thompson, S., Tangirala, K. and Eaddy, M.T. (2017) A Clinical and Economic Comparison of Rasburicase and Allopurinol in the Treatment of Patients with Clinical or Laboratory Tumor Lysis Syndrome. Clinical Lymphoma Myeloma and Leukemia, 17, 173-178. https://doi.org/10.1016/j.clml.2016.11.003

[4] Ayoub, I., Almaani, S., Brodsky, S., Nadasdy, T., Prosek, J., Hebert, L. and Rovin, B. (2016) Revisiting Medullary Tophi: A Link between Uric Acid and Progressive Chronic Kidney Disease? Clinical Nephrology, 85, 109-113. https://doi.org/10.5414/CN108663

[5] Bhadani, P.P., Sah, S.P., Sen, R. and Singh, R.K. (2006) Diagnostic Value of Fine Needle Aspiration Cytology in Gouty Tophi: A Report of 7 Cases. Acta Cytologica, 50, 101-104. https://doi.org/10.1159/000325904

[6] Gandhi, A., Aggarwal, S., Rajbongshi, A. and Arora, V.K. (2010) Bursal Gouty Tophus: Fine-Needle Aspiration Cytology Intrabursal Tophus on FNAC. Diagnostic Cytopathology, 38, 463-464.

[7] Tomar, R., Srivastava, R. and Arora, V.K. (2014) Relevance of synovial Cells in Gouty Tophus on Fine Needle Aspiration Cytology. Indian Journal of Pathology \& Microbiology, 57, 511-512. https://doi.org/10.4103/0377-4929.138811

[8] Singh, M., Maheshwari, B., Khurana, N. and Jain, S. (2012) Epidermal Inclusion Cyst in Breast: Is It So Rare? Journal of Cytology, 29, 169-172. https://doi.org/10.4103/0970-9371.101165

[9] Vanden Bussche, C.J. and Maleki, Z. (2014) Fine-Needle Aspiration of Squam- 
ous-Lined Cysts of the Pancreas. Diagnostic Cytopathology, 42, 592-599.

https://doi.org/10.1002/dc.23080

[10] Lorenz, E.C., Michet, C.J., Milliner, D.S. and Lieske, J.C. (2013) Update on Oxalate Crystal Disease. Current Rheumatology Reports, 15, 340.

https://doi.org/10.1007/s11926-013-0340-4 